\title{
Characterizing CMN1308, a Novel Strain of Bacillus amyloliquefaciens, for Potential Biological Control Application
}

\author{
Xuehua ZHANG ${ }^{1,3 a}$, Linling LI ${ }^{16}$, Shuiyuan CHENG ${ }^{1,2 *}$, Hua CHENG $^{1 *}$ \\ ${ }^{1}$ Huanggang Normal University, Economic Forest Germplasm Improvement and Comprehensive Utilization of Resources of Hubei Key Laboratory, Huanggang, 438000, \\ China;455262713@qq.com; lilinling1437@126.com;chenghua1437@126.com ('correspondingauthor) \\ ${ }^{2}$ Wuhan Polytechnic University, College ofBiology andPharmaceuticalEngineering, Wuhan, 430023, China;s_y_cheng@sina.com ("correspondingauthor) \\ ${ }^{3}$ College of Horticulture and Gardening, Yangtze University, Jingzhou, 434025, China; \\ ${ }^{a b}$ The authors contributed equally to thisstudy
}

\begin{abstract}
Fungal diseases of plants continue to contribute to heavy crop losses in spite of the best control efforts of plant pathologists. Breeding for disease-resistant varieties and the application of synthetic chemical fungicides are the most widely accepted approaches in plant disease management. CMN1308 strain of Bacillus amyloliquefaciens was isolated from healthy Chinese chestnut fruit, which has antibiosis and induced resistance to the prevention mechanism of pathogenic bacterium after picking. In order to evaluate the antibiosis mechanism, CMN1308 was fostered with the method of confrontculture. The antimicrobial

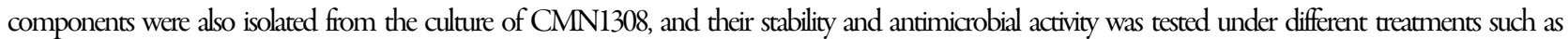
temperature, $\mathrm{pH}$ and UV. The results showed that $\mathrm{CMN} 1308$ displays advantages in regard to spatial competition against the major pathogens of chestnut, Rhizopus stolonifer, Fusarium solani,Stachybotrys chartarum, Cryphonectriaparasitica, Lasiodiplodiatheobromae, Penicillium expansum and Aspergillusniger. Among this, CMN1308 had the best antimicrobial activity against $P$. expansum, with the inhibitionzone diameter of $27.1 \mathrm{~mm}$. The antimicrobial material isolated from CMN1308 culture showed a strong inhibition to the growth of $P$. expansum hyphal and also had a good stability to high temperature, alkali media and UV, but was sensitive to acidic conditions. Furthermore, $\mathrm{CMN1} 308$ increased the peroxidase, polyphenol oxidase activity and reduced the MDA content in chestnuts after infecting by pathogenic fungi. Thus, producing antibiotic compounds and inducible resistance are the main factors that may explain the antibacterial mechanism ofCMN1308 on chestnut pathogenic. The results of this study might help to optimize the practical use of CMN1308 in the biological control of chestnut rot or other fruit rot infected by pathogenic fungi.
\end{abstract}

Keywords: antibacterial spectrum, Castanea mollissima, confront culture, endophyte, inhibition, pathogen, Penicillium, stability

\section{Introduction}

The Chinese chestnut (Castanea mollissima Blume) belongs to the Fagaceae family, being a traditional nut and one of the most popular foods across the world. The chestnut has a cultivation history of over 2,000 years in China with an important role in the economy. The chestnut fruit is considered of high nutritional value and it also has a long history of usage as a tonic food in traditional Chinese medicine (Borges et al., 2007; Zhang et al., 2011). However, browning and postharvest diseases are serious technical trouble in chestnut processing (Zhou et al., 2015). This problem cause enormous economic loss in Asia. Recently, synthetic fungicides are primarily used to control postharvest diseases of chestnut. However, the global trend appears to be shifting towards reducing the use of fungicides and hence, there is a strong public desire to seek safer and eco-friendly alternatives for reducing the decay loss in the harvested commodities (Mari et al., 2007).

Different Bacillus amyloliquefaciens strains are producers of antimicrobial substances with potential applications as biological control agents in order to suppress plant pathogens and pathogenic microorganisms in postharvest diseases of fruits (Caldeira et al., 2008; Benitez et al., 2012). B. amyloliquefaciens produces antimicrobial peptides that show a broad antimicrobial spectrum and the antagonistic effect of this strain against phytopathogenic fungi was also demonstrated recently (Benitez et al., 2010).

Based on the previous work (Hua, 2014), one strain of $B$. amyloliquefaciens (named CMN1308) was identified and characterized from the Chinese species of chestnut 'Meighong.' 
CMN1308 showed a strong inhibition to the growth of pathogenic bacterium after picking.

The aim of this work was to investigate the antibacterial spectrum, antibacterial mechanism of CMN1308 and the factors that might influence its antibacterial activity.

\section{Materials and Methods}

\section{Biological material}

Chestnut cultivar 'Meighong' was used in the experiment. The fruit were selected free of pests, diseases and wounds, and were collected from Luotian (east longitude 115 26', northern latitude $30^{\circ} 37^{\prime}$ ) Hubei province, China.

\section{Bacterium strain}

The CMN1308 (a type of Bacillus amyloliquefaciens) was isolated from the inside of chestnut fruit using the method of Hua (2014) and identified by morphological, physiological experiments and ITS (Internal transcribed spacer) gene analysis.

Cryphonectria parasitica, Rhizopus stolonifer, Stachybotrys chartarum, Lasiodiplodia theobromae, Fusarium solani, Penicillium expansum, Aspergillus niger, which were kept on the PDA (Potato dextrose agar) culture at $25^{\circ} \mathrm{C}$, were isolated from the natural infected chestnut fruit collected (Hua, 2014). Spore suspensions were prepared by 7 days PDA cultures with sterile distilled water. Spore concentrations were determined with a hemacytometer and adjusted to the required concentrations. The culture media were put in the autoclave at $121^{\circ} \mathrm{C}$ for $20 \mathrm{~min}$.

\section{Determination of CMN1308 antibacterialspectrum}

The antagonistic bacteria CMN1308 was activated in LB culture for $36 \mathrm{~h}$ at $37^{\circ} \mathrm{C}$. The confrontation culture method (Liu et al., 2008) was used to screen the antibacterial spectrum. The bacterial cake $(\mathrm{d}=6 \mathrm{~mm})$ was connected to four points $25 \mathrm{~mm}$ away from the central PDA culture medium, and the pathogenic fungus cell cake $(\mathrm{d}=6 \mathrm{~mm})$, which grew vigorously for 3-7 days on the PDA medium, was connected to the central of the culture plates. Afterwards, only the pathogenic fungus PDA plate was taken as the control (CK) and was cultured at $28^{\circ} \mathrm{C}$ for 3-5 days. The inhibition zone diameter (growth diameter for antagonistic bacteria) of each treatment was measured and the test was repeated three times.

Mycelia at the edge of the bacterial colony under the above treatment were chosen for microscopy, to observe the effect of antagonistic bacteria on mycelial growth, with mycelia cultured normally in PDA medium as a control group (Chen et al., 2009).

\section{Determination of inbibitory effect of CMN1308 under different conditioningfluid}

The filtering paper method (Zhang et al., 2009) was adopted to measure the antibacterial activity of different components in antagonistic bacteria CMN1308. Several sheets of round filter paper $(\mathrm{d}=6 \mathrm{~mm})$ were sterilized and dried for standby applications. A pipette was employed to take $200 \mu \mathrm{L} P$. expansum suspension which was added to the PDA plate, spreading it evenly using a coating bar. Then, sheets of filter paper were taken by sterile tweezers and soaked into the prepared CMN1308 broth, bacterial suspension and sterile filtrate, for a few minutes. Afterwards, sheets of filter paper were taken by tweezers and put on to the inoculated plates. Using sterile water as a control, the test was repeated three times and the culture was placed at $37^{\circ} \mathrm{C}$ in the incubator, for $2-3$ days. Further, the size of the inhibition zone was observed and measured.

\section{Growth curve and inbibition time-history curve of CMN1308 in LB media \\ CMN1308 strains were inoculated into LB media (100 mL)} contained in a $250 \mathrm{~mL}$ flask at $37^{\circ} \mathrm{C}$, on a rotary shaker at 160 rpm. $10 \mathrm{~mL}$ culture samples were collected from each bacterium solution bottle at the time points from $6,12,24,36,48,60,72$, and $84 \mathrm{~h}$. The operation was repeated three times (Li, 2011).

The absorbance of bacterium solution at $600 \mathrm{~nm}$ was measured using the $722 \mathrm{~S}$ visible spectrophotometer. Taking the uninoculated LB broth as the control, with incubation time as the abscissa and concentration of bacteria as the vertical axis, a growth curve was drawn.

After fermenting for $6,12,24,36,48,60,72$, and $84 \mathrm{~h}$ respectively, $5 \mathrm{~mL}$ of fermentation broth was centrifuged and the antibacterial activity of the supernatant was measured by using the filter paper method (Zhang et al., 2009), in order to determine the peak of generating inhibitory substances.

Preparation of CMN1308 fermentation broth, bacterial suspension and sterile filtrate

The antagonistic bacteria was streaked onto LB plates and incubated at $37{ }^{\circ} \mathrm{C}$ for $12 \mathrm{~h}$. A single colony was picked and inoculated into LB liquid media in a $100 \mathrm{ml} / 250 \mathrm{ml}$ flask at $37{ }^{\circ} \mathrm{C}$, on a rotary shaker at $160 \mathrm{rpm}$, for $48-60 \mathrm{~h}$. Then fermentation broth of antagonistic bacteria was made. The broth solution was thus centrifuged at 10,000 rpm for $10 \mathrm{~min}$. The bacterial cells were collected and washed twice with sterile saline, and finally made into the bacterial suspension. A hemocytometer was used to determine the concentration of cells in the suspension, and the desired concentration was adjusted by sterile saline for standby application. After centrifugation, the supernatant was sterilized by filtration through $0.22 \mu \mathrm{m}$ poresized filters and the sterile filtrate was obtained (Xi, 2006).

\section{Stability testing of CMN1308 antagonistic substances}

Temperature treatment: each of $5 \mathrm{~mL}$ sterile filtrates were taken by sterile tubes and treated at $20,40,60,80$, and $100^{\circ} \mathrm{C}$ for $60 \mathrm{~min}$. After the filtrates have cooled to room temperature, the inhibitory effect on $P$. expansum was tested by the filter paper method (Zhang et al., 2009). Taking the untreated sterile filtrates stored at $4^{\circ} \mathrm{C}$ as the control, each treatment was repeated 3 times (Li, 2013).

Acid and alkali treatment: each of $5 \mathrm{~mL}$ sterile filtrate was taken and added into sterile centrifuge tubes. $1 \mathrm{M} \mathrm{NaOH}$ or $\mathrm{HCl}$ was used to adjust the $\mathrm{pH}$ values to $2,3,4,5,6,8,9,10,11$, and 12 , respectively. After standing for $30 \mathrm{~min}$, the inhibitory effect on $P$. expansum was tested. Taking untreated sterile filtrates $(\mathrm{pH} 7.0)$ as the control, each treatment was repeated three times (Tang et al., 2011).

UV irradiation treatment: each of the $5 \mathrm{~mL}$ sterile filtrate was taken and put into 4 sterile glass fishes for treatment at a distance of $15 \mathrm{~cm}$ from the UV light $\left(30 \mu \mathrm{W} / \mathrm{cm}^{2}\right)$, for $10 \mathrm{~min}$, $20 \mathrm{~min}, 30 \mathrm{~min}, 40 \mathrm{~min}$, respectively. Taking sterile filtrates not treated with UV as the control, the inhibitory effect on $P$. expansum was tested and each treatment was repeated three times (Bu, 2012). 
62

Statistical analysis

The data were calculated by the analysis of the variance (ANOVA) in SPSS software. Mean were compared with Duncan's multiple range test at $\mathrm{P} \leq 0.05$

\section{Results} picking

The inhibition effect of CMN 1308 to pathogenic bacterium after

The antibacterial analysis of CMN1308 was carried out after picking the chestnuts, using $P$. expansum, $A$. niger, $C$. parasitica and F. solani as the pathogenic bacterium (Fig. 1). The chestnut treated with fermentation broth, resuspension, and sterile filtrates of CMN1308 respectively, had a lower infection rate than the control. Wherein, the fermentation broth showed the best biological control to the four fungi, the infection rate was $28.3 \%$ to P. expansum, $35 \%$ to $F$. solani, $31.7 \%$ to $C$. parasitica and $50 \%$ to $A$. niger respectively, the sterile filtrates had a higher infection to the four fungi than the resuspension treatment. After CMN1308 treatment, the $P$. expansum showed the lowest infection inner chestnuts compared with the other three pathogen fungi, whatever it was fermentation, resuspension or sterile filtrates ofCMN1308.

\section{Antibacterialspectrum analysis of CMN1308}

The antibacterial activity of CMN1308 on $R$. stolonifer, $F$. solani, S. chartarum, C. parasitica, L. theobromae, P. expansum and $A$. niger was tested using the method of plate confrontation culture (Liu et al., 2008). The results showed that CMN1308 exhibited different degrees of inhibition on the seven pathogenic fungi, the inhibition zone ranging from 10 to $30 \mathrm{~mm}$ (Fig. 2). Wherein, CMN1308 had the best inhibition effect on $P$. expansum for which the average inhibition zones reached $27.1 \mathrm{~mm}$ (Table 1).

The mycelium growth of pathogenic fungi was significantly inhibited by forming the apparent inhibition zones by CMN1308. In addition, a significant hyphal breakage happened when observing the mycelia of $L$. theobromae under the microscope (Fig. 3), indicating that CMN1308 strains showed some inhibitory effects on bacteria mycelium.

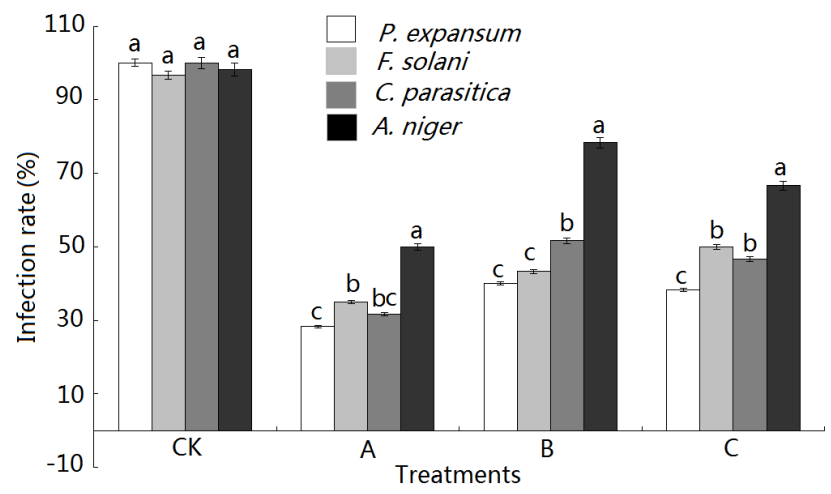

Fig. 1. The inhibition effects of Bacillus amyloliquefaciens strain on main chestnut pathogens with different treatments (A, B, C). Values are the mean of 30 samples and bars represent standard errors. Means with different letters are significantly different at $\mathrm{P} \leq 0.05$ by Duncan's multiple rang test. CK: the water control; A: treatment with 108 $\mathrm{CFU} / \mathrm{mL}$ fermentation broth of CMN1308; B: 108CFU/mL the resuspension of CMN1308; C: The sterile filtrates of CMN1308
Impact of CMN1308 on POD, PPO Activity and MDA Content in chestnut

POD (Peroxidase) activity in chestnut had a dynamic change after different treatments (Fig. 4). For the control group treated with water, the activity of POD was relatively stable and had a lower level. After 2 days of treatment, the infection with pathogens, CMN1308 or the combine of them caused improvement of POD activity in chestnuts. After 3 days of infection, the POD activity reached the highest level, which was 1.4 times, 1.5 times, 1.9 times of the control group, respectively. With longer time of
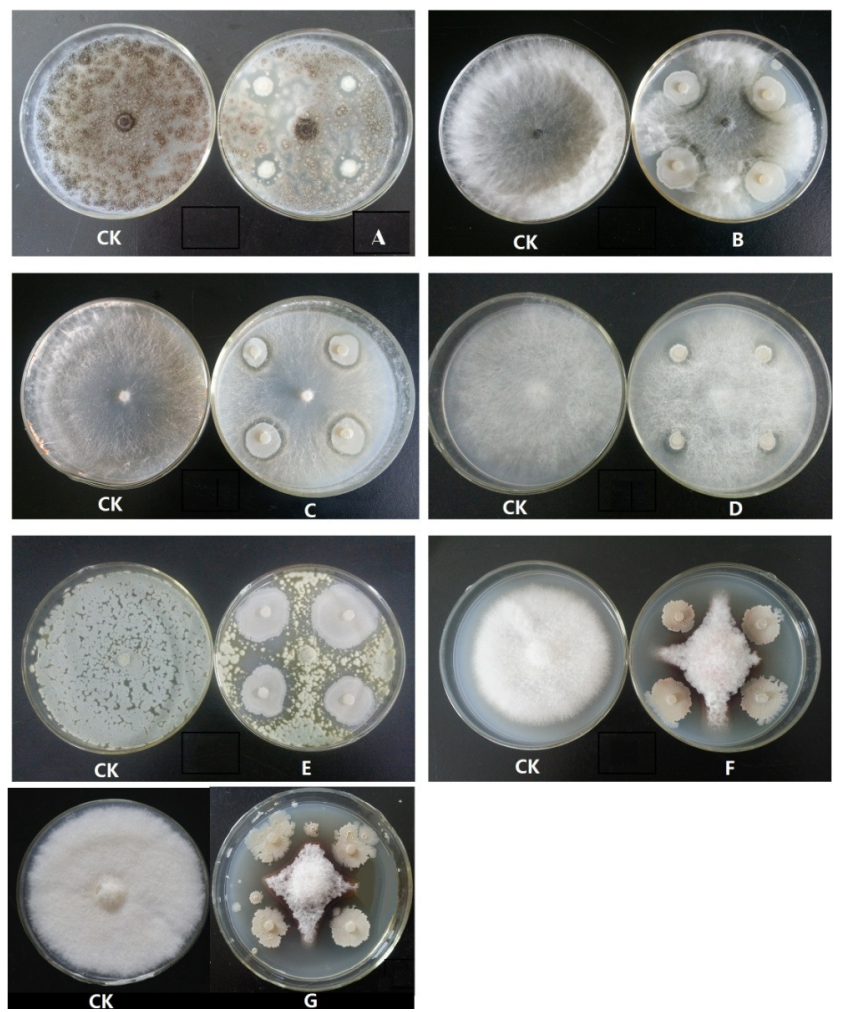

Fig. 2. Antagonistic bacteria CMN1308 inhibition of pathogenic fungi. The CMN1308 disk (d=6 mm) was inoculated to four points $25 \mathrm{~mm}$ away from the central PDA culture plate, and the pathogenic fungus cell disk $(\mathrm{d}=6 \mathrm{~mm})$ was infected on the centre of the PDA plate, which grew vigorously at $28^{\circ} \mathrm{C}$ for 3-7 days. Only the pathogenic fungus PDA plate was taken as the control $(\mathrm{CK})$ and was cultured at $28^{\circ} \mathrm{C}$ for $3-5$ days. The inhibition zone diameter (growth diameter for antagonistic bacteria) of each treatment was measured and the test was repeated three times; A: Aspergillus niger; B: Lasiodiplodia theobromae; C: Cryphonectria parasitica; D: Rhizopus stolonifer; E: Penicillium expansum; F: Fusarium solani; G: Stachybotrys chartarum

Table 1. Antagonistic bacteria CMN1308 inhibition zones of pathogenic fungi

\begin{tabular}{lc}
\hline Pathogenic fungi tested & Diameter of inhibition zone $(\mathrm{mm})$ \\
\hline Cryphonectria parasitica & 17.0 \\
Lasiodiplodia theobromae & 18.6 \\
Rhizopus stolonifer & 10.9 \\
Penicillium expansum & 27.1 \\
Aspergillus niger & 14.4 \\
Fusarium solani & 20.4 \\
Stachybotrys chartarum & 20.9 \\
\hline
\end{tabular}




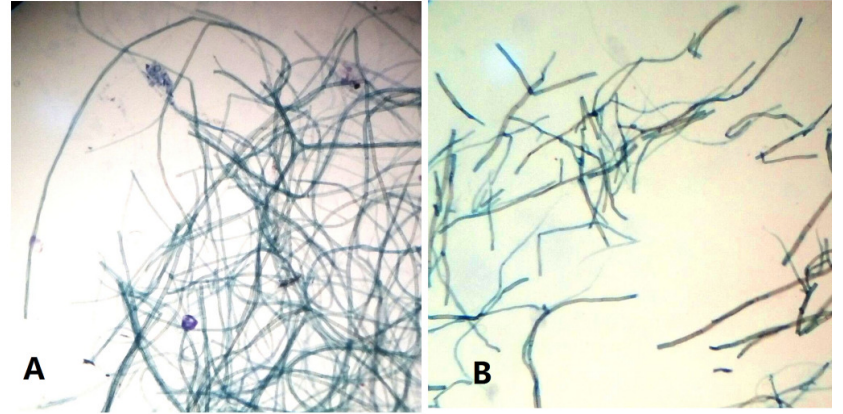

Fig. 3. Inhibition of CMN1308 on the mycelium growth of Lasiodiplodia theobromae; A: Normal growth of mycelium, B: Confront culture edge mycelium

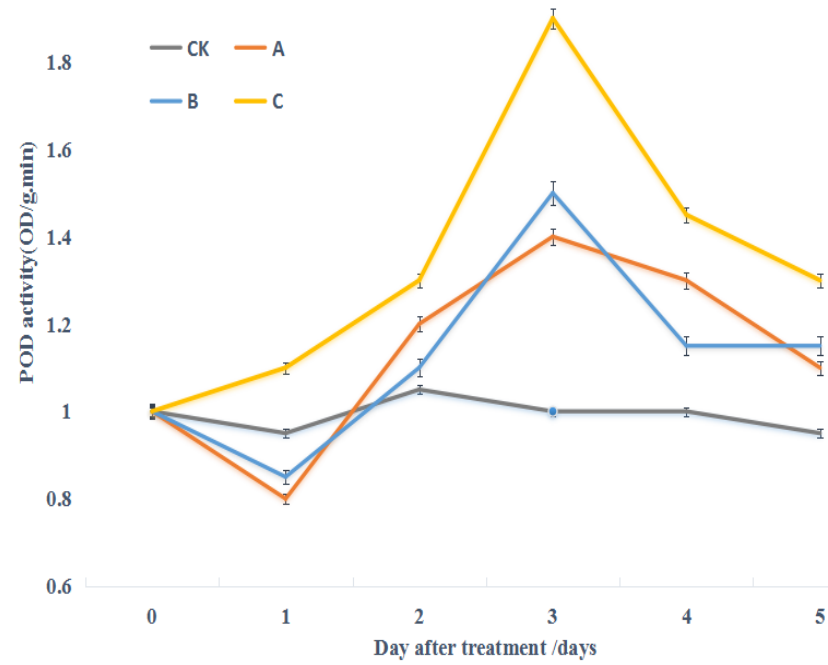

Fig. 4. The POD activity analysis with different antagonistic microbes inoculation in chestnut; $\mathrm{CK}$ : the control, A: pathogenic fungi, B: CMN1308, C: pathogenic fungi and CMN1308 together

treatment (at 5 days), the enzyme activity gradually decreased and returned to the original level. To conclude, CMN1308 showed an effective inducer of POD activity under the presence of pathogens, but with a short lasting period.

PPO (Polyphenol oxidase) activity of chestnuts also had a dynamic change after different inoculations (Fig. 5). Compared to the control, chestnut PPO activity rose, fell and rose again within 5 days when inoculated with CMN1308, showing no pattern to follow. It reached peaks at 1 and 3 days of treatment, 1.27 and 1.51 times of the control, respectively, and down to the same as control after 5 days. Pathogen inoculation treatment alone could induce increases in chestnut PPO activity to a certain extent, reaching a peak at 3 days, which was 1.75 times the enzyme activity of the control group, and then gradually declining, showing a tendency to return to normal after 5 days. For treatments of CMN1308 and pathogens, PPO activity gradually enhanced steadily in the first two days and reached a peak in the third day after a sharp increase, which was 2.78 the enzyme activity of the control. It showed that under the presence of pathogens, CMN1308 could be an effective inducer of PPO activity, and had a certain long persistence.

Five days post-inoculation with pathogenic fungi, CMN1308, or both, the MDA (Malondialdehyde) content had a significant change in chestnuts (Fig. 6). In the control group MDA content was relatively stable. After combined inoculation of CMN1308

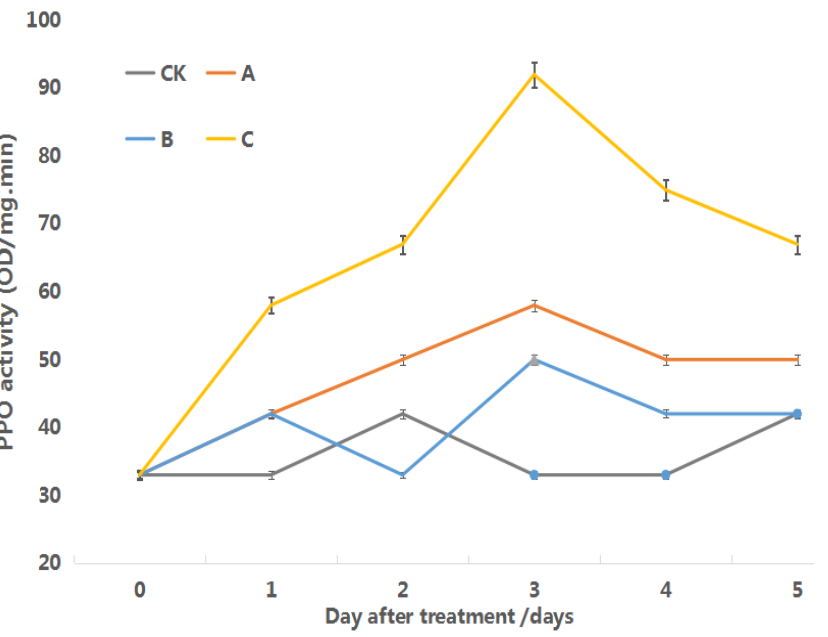

Fig. 5. The PPO activity analysis with different antagonistic microbes inoculation in chestnut; $\mathrm{CK}$ : the control, A: pathogenic fungi, B: CMN1308, C: pathogenic fungi and CMN1308 together

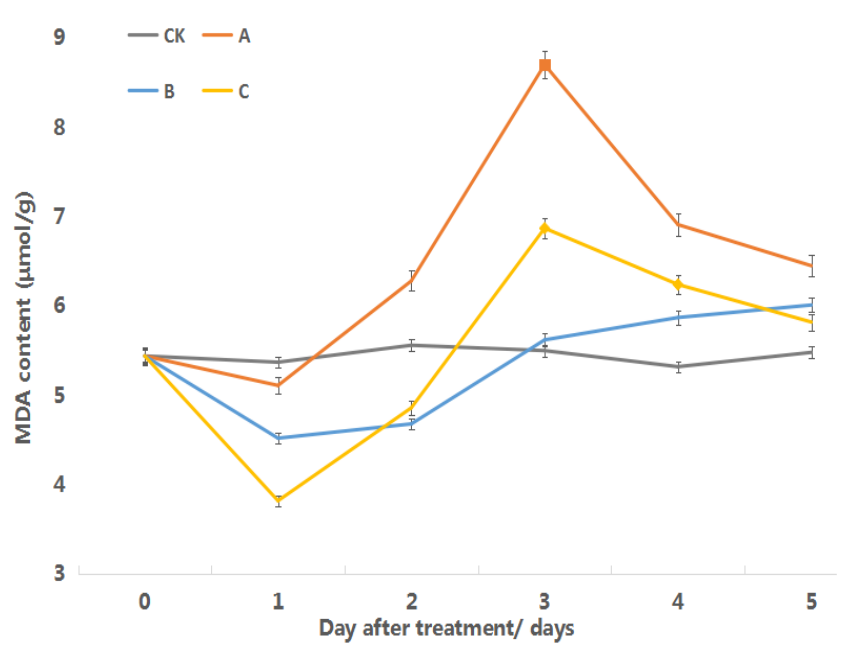

Fig. 6. The MDA contents with different antagonistic microbes inoculation in chestnut; $\mathrm{CK}$ : the control, A: pathogenic fungi, B: CMN1308, C: pathogenic fungi and CMN1308 together

and pathogens, MDA concentration declined rapidly in the first two days by $29 \%$ and $13 \%$, respectively. Later, MDA content rose weakly, and reached the control level after 5 days. After single treatment of inoculated pathogens, chestnut MDA content began to rapidly rise at 2 days, reaching the highest value at 3 days, an increase of $58 \%$ compared to $\mathrm{CK}$; then it began to decline and tended to control levels after 5 days. After CMN1308 treatment, the MDA content of chestnut was lower than that of control level within 3 days and slowly increased later, but it has remained at a low level, indicating that CMN1308 caused almost no damage or unobvious damage to chestnut within the measured time. These results showed that single and simultaneous induction of CMN1308 and pathogens can make chestnut MDA content reduce significantly, and therefore, CMN1308 strains can effectively reduce the increase in MDA content caused by pathogen infection and lessen the damaging effects of bacteria on the host cell membrane, thereby reducing or inhibiting the occurrence of diseases. 
64

\section{Antibacterial effects of different treatment solutions of CMN1308}

Different solutions of CMN1308 had inhibitory effects on $P$. expansum; the inhibition zone diameters were ranked as fermentation broth $>$ sterile filtrates $>$ bacterial suspension, which indicated that CMN1308 and its metabolites had strong antagonist effect to $P$. expansum (Table 2).

\section{Growth curve of CMN1308 in LB broth}

The culture of CMN1308 enter logarithmic phase when it was incubated for $24 \mathrm{~h}$ and the biological yield reached maximum at $48 \mathrm{~h}$ (Fig. 7); OD600 absorption value fetched the highest peak at 1.7307 . The culture had the strongest inhibition effect on $P$. expansum when it was incubated for $60 \mathrm{~h}$, the inhibition zone diameter being $23.5 \mathrm{~mm}$. Later, the activity of antibacterial substances began to decline after $60 \mathrm{~h}$, indicating that the antibacterial substances lagged behind the increased logarithmic phase of bacteria. After $48 \mathrm{~h}$ culture, CMN1308 growth slowly, but the antibacterial substances were still in the process of accumulation. Therefore, it would be recommended to use more antibacterial substances when CMN1308 cultured for 48-60 h.

\section{Stability testing of CMN1308 antagonistic substances}

According to Growth curve results, sterile filtrates prepared by CMN1308 fermentation broth showed inhibitory effects to pathogens, and there were various metabolites produced by antagonistic bacteria in sterile filtrates. Thus, CMN1308 and the antimicrobial substances all influenced antagonistic mechanisms. The results of stability testing of CMN1308 antagonistic substances are as follows.

\section{Thermal stability of antimicrobial substances}

CMN1308 sterile filtrates still had strong inhibitory effects on P. expansum after five different temperature treatments (Table 3).

Table 2. CMN1308 different treatment solutions' inhibitory effect on Penicillium expansum

\begin{tabular}{lcccc}
\hline Treatment & $\begin{array}{c}\text { Water } \\
\text { (control) }\end{array}$ & $\begin{array}{c}\text { Fermen- } \\
\text { tation } \\
\text { broth }\end{array}$ & $\begin{array}{c}\text { Bacterial } \\
\text { resuspension }\end{array}$ & $\begin{array}{c}\text { Sterile } \\
\text { filtrate } \\
\mathrm{s}\end{array}$ \\
\hline $\begin{array}{l}\text { Diameter of } \\
\text { antibacterial }(\mathrm{mm})\end{array}$ & 0 & 17.7 & 11.5 & 11 \\
\hline
\end{tabular}

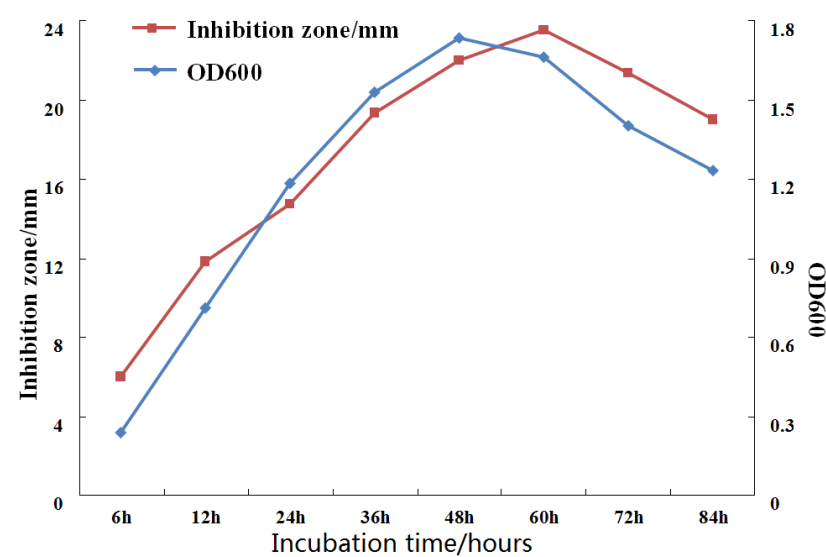

Fig. 7. Antibacterial activity curve and OD600 absorption curve of CMN1308
The antagonistic substances of CMN1308 exhibited the strongest antibacterial activity at $40{ }^{\circ} \mathrm{C}$, even though there were no significant differences at the 0.05 level compared to the control. As the temperature increased, the antibacterial activity showed a slowly downward trend. On the whole, the antimicrobial substances still presented strong antimicrobial activity within the range of $4-100^{\circ} \mathrm{C}$ and the relative inhibition rate was above $85 \%$. This section indicated that antibacterial substances of CMN1308 had strong thermal stability within $4-100^{\circ} \mathrm{C}$.

\section{pHstability of antimicrobial substances}

After different $\mathrm{pH}$ treatments, $\mathrm{CMN} 1308$ sterile filtrates showed variant inhibitory effects (Table 4). The antagonistic filtrates presented the best antibacterial effects in neutral conditions ( $\mathrm{pH}$ 6-8); good antibacterial effects and stability were also noted under alkali condition ( $\mathrm{pH}$ 9-12). The filtrates produced precipitation and showed poor antibacterial effects under acidic conditions at $\mathrm{pH} 2-5$, indicating that antibacterial substances of CMN1308 were unstable under acidic conditions.

\section{UV stability of antimicrobial substances}

The sterile filtrates showed antimicrobial activity after treated with ultraviolet irradiation for different time periods (Table 5).

Table 3. Inhibitory effect of CMN1308 sterile filtrate treated at different temperatures on Penicillium expansum

\begin{tabular}{ccc}
\hline Temperature $\left({ }^{\circ} \mathrm{C}\right)$ & $\begin{array}{c}\text { Diameter of } \\
\text { antibacterialzone }(\mathrm{mm})\end{array}$ & $\begin{array}{c}\text { Relative bacteriostatic } \\
\text { rate }(\%)\end{array}$ \\
\hline $\mathrm{CK}\left(4^{\circ} \mathrm{C}\right)$ & 14.8 & 100.0 \\
$20^{\circ} \mathrm{C}$ & 14.7 & 99.3 \\
$40^{\circ} \mathrm{C}$ & 15 & 101.4 \\
$60^{\circ} \mathrm{C}$ & 13.7 & 92.6 \\
$80{ }^{\circ} \mathrm{C}$ & 13.5 & 91.2 \\
$100{ }^{\circ} \mathrm{C}$ & 12.6 & 85.1 \\
\hline
\end{tabular}

Table 4. The stability of CMN1308 sterile filtrate effect on Penicillium expansum, in different $\mathrm{pH}$ condition

\begin{tabular}{ccc}
\hline $\mathrm{pH}$ & $\begin{array}{c}\text { Diameter of antibacterial zone } \\
(\mathrm{mm})\end{array}$ & $\begin{array}{c}\text { Relative bacteriostatic rate } \\
(\%)\end{array}$ \\
\hline 2 & 6 & 33.0 \\
3 & 6 & 33.0 \\
4 & 6.3 & 35.0 \\
5 & 6.7 & 37.0 \\
6 & 18.6 & 103.3 \\
$\mathrm{CK}(7)$ & 18 & 100.0 \\
8 & 18.7 & 103.9 \\
9 & 17.8 & 98.9 \\
10 & 17.4 & 96.7 \\
11 & 16.3 & 90.6 \\
12 & 14.9 & 82.8
\end{tabular}

Table 5. The stability of CMN1308 sterile filtrate effect on Penicillium expansum, after different UV radiation time

\begin{tabular}{ccc}
\hline $\begin{array}{c}\text { Treatment time by } \\
\text { UV }\end{array}$ & $\begin{array}{c}\text { Diameter of } \\
\text { antibacterial zone }(\mathrm{mm})\end{array}$ & $\begin{array}{c}\text { Relative bacteriostatic rate } \\
(\%)\end{array}$ \\
\hline CK & 18.5 & 100.0 \\
$10 \mathrm{~min}$ & 17.8 & 96.2 \\
$20 \mathrm{~min}$ & 17.3 & 93.5 \\
$30 \mathrm{~min}$ & 17.0 & 91.9 \\
$40 \mathrm{~min}$ & 17.2 & 93.0 \\
$60 \mathrm{~min}$ & 16.8 & 90.8 \\
\hline
\end{tabular}


The antibacterial activity showed a feeble downward trend with the increase of UV irradiation time. The relative bacteriostatic rate was still $90.8 \%$ after UV irradiation for $60 \mathrm{~min}$, showing no significant differences at the 0.05 level compared to the control. This means the antibacterial substances of CMN1308 were not sensitive to UV irradiation.

\section{Discussion}

Due to environmental influence and other factors, antagonistic microorganisms isolated from soil and other environments typically have dissatisfactory control efficacy of diseases. Endophytic bacteria refer to a class of microorganisms living in plant tissues or tissue gaps, but causing no harm to plants or plant diseases. Endophytic bacteria are less influenced by the external environment, so they can grow effectively inside and on the surface of fruits and vegetables, and can better adapt to the fruit and vegetable storage environment than the microorganisms in external environments (Chebotar et al., 2015). Moreover, the existence of microbial-mediated induced resistance has also been widely demonstrated for endophytic fungi and bacteria (Schena et al., 2003). Innocuous bacterial strains that may produce antimicrobial substances are of great interest as natural preservatives that confine or inhibit different pathogens or spoilage microorganisms. The non-toxigenic Bacillus species are considered safe and could be used for agricultural, human and veterinary purposes (Benitez et al., 2012). The objectives of this study were to identify the CMN1308 strain antimicrobial spectrum, its mechanism and antimicrobial factor produced, as well as to evaluate its antimicrobial activity, stability and inducible resistance to chestnut.

According to the results, B. amylolyticus CMN1308 showed a broad bacteriostatic spectrum when combined with its antimicrobial factor of metabolism. Meng (2012) results showed that the compounds present in the culture broth of BAC03 ( $B$. amyloliquefaciens) were more tolerant to adverse conditions than extracted ASP (Ammonium sulfate-precipitated material) from the bacterium; this may be because the living cells can protect the compounds from degradation and continue to produce the chemicals. In this study, it was also found that the antimicrobial activity decrease when the suspension of bacterium or the extracted culture medium was used alone. It is possible that other bacteriostatic compounds are present in the culture medium.

Meng (2012) found that the antimicrobial activity of either a B. amyloliquefaciens strain liquid culture or the ASP fraction was stable under a wide range of temperatures and $\mathrm{pH}$ levels, after incubation by itself or with several chemicals, but was reduced by proteinases treatment, thus LCI protein being associated with some of the antimicrobial activity. The acid-precipitated fraction showed a small level of inhibition against Streptomyces spp. In this study, CMN1308 had a high stability to a wide range of temperature, $\mathrm{pH}$ and UV condition, but antimicrobial of filter liquor produced precipitate and the activity decreased quickly at acidic condition ( $\mathrm{pH}$ 2-5). Seeing from the microlevel, CMN1308 inhibit the hyphal growth of several postharvest fungi by competition the nutrition and space.

It has not been reported that $B$. amylolyticus showed character of induce resistance to pathogens. The level of defense enzyme activity is an important indicator of disease resistance of plants. In the defense enzymes, POD is one of the protective enzymes for plants to resist reactive oxygen damage (Meloni et al., 2003). In addition, POD is also involved in the synthesis of lignin and promotes lignifications of the invaded tissues, thus forming a physical barrier to defense against the invading pathogen (Jang et al., 2004). PPO forms quinines toxic to pathogens, thus directly having an antiviral action ( $\mathrm{Li}$ and Steffens, 2002). Further, reactive oxygen metabolism loses balances when plants are subjected to damage, and MDA content can reflect the degree of plant damage (Soleimanzadeh et al., 2010).

\section{Conclusion}

The experimental results showed that stimulated by major postharvest pathogens, CMN1308 can significantly enhance the activity of defense enzymes of Peroxidase and Polyphenol oxidase in chestnuts, enhance their resistance to pathogens, and can also effectively reduce the increasing Malondialdehyde level caused by major pathogens, so as to maintain a relatively stable physiological state. Therefore, producing antibiotic compounds and inducible resistance are the main factors that may explain the antibacterial mechanism of CMN1308 on chestnut pathogenic. In conclusion, this research has indicated that CMN1308 would be a good biological control agent for chestnut postharvest diseases biocontrol and other fruits in commercial field.

\section{Acknowledgments}

This study was supported by the Foundation for innovative research group of Natural Science of Hubei Province (2010CBB03901), Youth Foundation for innovative research of Hubei Educational Office (Q20132909) and Foundation for Industry-University Research Cooperation of Huanggang Normal University (2012025903).

\section{References}

Benitez LB, Velho RV, Motta AdS, Segalin J, Brandelli A (2012). Antimicrobial factor from Bacillus amyloliquefaciens inhibits Paenibacillus larvae, the causative agent of American foulbrood. Archives of Microbiology 194(3):177-185.

Benitez LB, Velho RV, Lisboa MP, MedinaLFBrandelli A (2010). Isolation and characterization of antifungal peptides produced by Bacillus amyloliquefaciens LBM5006. The Journal of Microbiology 48(6):791797.

Borges OP, Soeiro CJ, Reis CP, Paula SA (2007).Lipid and fatty acid profiles of Castanea sativa Mill. chestnuts of 17 native Portuguese cultivars. Journal of Food Composition and Analysis 20(2):80-89.

$\mathrm{Bu}$ TT (2012). The study on colonization of endophytic bacteria Y13 on camellia and bacteriostatic mechanism of endophytic bacteria Y13 to Camellia anthracnose. Master D Thesis, Central South University of Forestry and Technology, Changsha China.

Caldeira AT, Feio SS, Arteiro JM, Coelho AV, Rosseiro JC (2008). Environmental dynamics of Bacillus amyloliquefaciens CCMI 1051 antifungal activity under different nitrogen patterns. Journal of Applied Microbiology 104(3):808-816.

Chebotar VK, Malfanova NV, Shcherbakov AV, Ahtemova GA, Borisov 
AY, Lugtenberg B, Tikhonovich IA (2015). Endophytic bacteria in microbial preparations that improve plant development. Applied Biochemistry and Microbiology 51(3):271-277.

Chen L, Nawaer M, Gong Q, Miu W, Nuer Z, Liu H (2009). Molectial Identification and Mechanism of Antagonistic Bacteria A178. Chinese Agricultural Science Bulletin 25(22):241-244.

Hua J (2014). Study on screening, identification of postharvest pathogens of chestnut and the antiseptic technique. Master Thesis, Wuhan Institute of Technology, College of Life Science, Wuhan, China.

Jang IC, Park SY, Kim KY, Kwon SY, Kim JG, Kwak SS (2004). Differential expression of 10 sweetpotato peroxidase genes in response to bacterial pathogen, Pectobacterium chrysanthemi. Plant Physiology and Biochemistry $42(5): 451-455$.

Li B (2013). Purification and characteristic analysis of antifungal substances from Bacillus amyloliquefaciens X-278. Master Thesis, Agricultural University of Hebei, BaodingChina.

Li L, Steffens JC (2002). Overexpression of polyphenol oxidase in transgenic tomato plants results in enhanced bacterial disease resistance. Planta 215(2):239-247.

Li X (2011). Isolation, screening and development of biocontrol agent of endophytic antagonistic bacteria to camellia soft rot disease. Master Thesis, Central South University of Forestry and Technology, ChangshaChina.

Liu H, Li C, Xu Y (2008). Series strain of biocontrol bacteria had good pathogen inhibiting chat to pathogenic fungi. Soybean Bulletin (1):1013.

Mari M, Neri F, Bertolini P (2007). Novel approaches to prevent and control postharvest diseases of fruits. Stewart Postharvest Review 3(6):17.

Meloni DA, Oliva MA, Martinez CA, Cambraia J (2003). Photosynthesis and activity of superoxide dismutase, peroxidase and glutathione reductase in cotton under salt stress. Environmental and Experimental Botany 49(1):69-76.
Meng Q, Jiang H, Hanson L, Hao J (2012). Characterizing a novel strain of Bacillus amyloliquefaciens $\mathrm{BAC03}$ for potential biological control application.Journal of Applied Microbiology 113(5):1165-1175.

Schena L, Nigro F, Pentimone I, Ligorio A, Ippolito A (2003). Control of postharvest rots of sweet cherries and table grapes with endophytic isolates of Aureobasidium pullulans. Postharvest Biology and Technology30(3):209-220.

Soleimanzadeh H, Habibi D, Ardakani M, Paknejad F, Rejali F (2010). Effect of potassium levels on antioxidant enzymes and malondialdehyde content under drought stress in sunflower (Helianthus annuus L.). American Journal of Agricultural and Biological Sciences 5(1):56-63.

Tang R, Zhang X, Shi X, Wang S (2011). Primary study on the antibiotic mechanism and substance of M-14 strain against Chinese cabbage soft rot.Northern Horticulture (in Chinese) 20:38-39.

Xi Z (2006). The study of biocontrol and mechanism of action on postharvest diseases of circus fruits by Bacillus subtilis. Master Thesis, Zhejiang University, Hangzhou China.

Zhang J, Wang Y, Zhang F, Wang F (2009). Mensuration the antiseptic activity of extracts from Artemisia annua $\mathrm{L}$. to mold with the filter paper method. Hubei Agricultural Sciences (in Chinese) 48(5):1153-1154.

Zhang M, Chen H,Zhang Y (2011). Physicochemical, thermal, and pasting properties of Chinese chestnut (Castanea mollissima $\mathrm{Bl}$.) starches as affected by different drying methods. Starch-Stärke 63(5):260-267.

Zhou D, Li L, Wu Y, Fan J, Ouyang J (2015). Salicylic acid inhibits enzymatic browning of fresh-cut Chinese chestnut (Castanea mollissima) by competitively inhibiting polyphenol oxidase. Food Chemistry 171(15):19-25. 